\title{
Monitoring of Non-Linear Ground Movement in an Open Pit Iron Mine Based on an Integration of Advanced DInSAR Techniques Using TerraSAR-X Data
}

\author{
José Claudio Mura ${ }^{1}$, , Waldir R. Paradella ${ }^{1}$, Fabio F. Gama ${ }^{1}$, Guilherme G. Silva ${ }^{1}$, \\ Mauricio Galo ${ }^{2}$, Paulo O. Camargo ${ }^{2}$, Arnaldo Q. Silva ${ }^{3}$ and Aristotelina Silva ${ }^{4}$ \\ 1 National Institute for Space Research (INPE), São José dos Campos, SP 12227-010, Brazil; \\ waldir@dsr.inpe.br (W.P.); fabio@dpi.inpe.br (F.G.); guilherme.gregorio@inpe.br (G.S.) \\ 2 São Paulo State University (FCT/UNESP), Presidente Prudente, CEP 19060-900, Brazil; \\ galo@fct.unesp.br (M.G.); paulo@fct.unesp.br (P.C.) \\ 3 Federal University of Pará (IG/UFPA), Belém, CEP 66075-110, Brazil; arnaldoq@ufpa.br \\ 4 Vale S. A. (DIFN/GEDEN/GAGHN), Serra dos Carajás, CEP 68516-000, Brazil; aristotelina.silva@vale.com \\ * Correspondence: mura@dpi.inpe.br; Tel.: +55-12-3208-6517; Fax: +55-12-3208-6449
}

Academic Editors: Zhong Lu and Prasad S. Thenkabail

Received: 11 January 2016; Accepted: 9 May 2016; Published: 12 May 2016

\begin{abstract}
This work presents an investigation to determine ground deformation based on an integration of DInSAR Time-Series (DTS) and Persistent Scatterer Interferometry (PSI) techniques aiming at detecting high rates of linear and non-linear ground movement. The combined techniques were applied in an open pit iron mine located in Carajás Mineral Province (Brazilian Amazon region), using a set of 33 TerraSAR-X-1 images acquired from March 2012 to April 2013 when, due to a different deformation behavior during the dry and wet seasons in the Amazon region, a non-linear deformation was detected. The DTS analysis was performed on a stack of multi-look unwrapped interferograms using an extension of the SVD (Singular Value Decomposition), where a set of additional weighted constraints on the acceleration of the displacement was incorporated to control the smoothness of the time-series solutions, whose objective was to correct the atmospheric phase artifacts. The height errors and the deformation history provided by the DTS technique were used as previous information to perform the PSI analysis. This procedure improved the capability of the PSI technique to detect non-linear movement as well as to increase the numbers of point density of the final results. The results of the combined techniques are presented and compared with total station/prisms and ground-based radar (GBR) measurements.
\end{abstract}

Keywords: DInSAR time-series; PSI; surface movement; open pit iron mine

\section{Introduction}

The use of standard Differential SAR Interferometry (DInSAR) technique for monitoring surface deformation has been applied since the early 1990s [1-5]. Multi-temporal acquisitions improve the capability for detecting temporal change of deformation phenomena. To take advantage of it, DInSAR Time-Series (DTS) have been proposed and successfully used [6-10]. The PSI (Persistent Scatterer Interferometry) approach [11-13], based on a stack of differential interferograms, relies on identifying pixels whose scattering properties do not vary much with time and look angle, allowing a temporal analysis of the interferometric phase of individual point targets as well as providing accurate information related to surface target displacements. PSI provides better accuracy than the DTS technique. The former can better model and diminish the effect of the atmospheric phase, which 
is related to the path delay heterogeneity during acquisition times, whereas the latter can detect larger non-linear deformation and provide more homogeneous and extensive information related to the ground deformation, albeit at the expense of a loss in spatial resolution. Several improvements have been made in the PSI technique to ameliorate its performance [14,15].

Instabilities can be expected from any mining activity. Open pit operations usually have significant extensive areas and can also influence large portions of terrain adjacent to the pit crest. Rock mass movements and surface deformations potentially lead to slope instabilities or wall failures due to regular open pit mining operations. Advanced DInSAR techniques have been used to measure ground movement in underground mines [16-20], as well as in open pit mines [21-24], providing spatial coverage and reliable measurements of ground movement.

The PSI processing technique involves the temporal phase-unwrapping process, which is a very important stage to accurately determine ground movement. Limitations in this process can be found especially for detection of high movement rates. By using a priori information regarding the topographic phase error and phase displacement model, temporal phase-unwrapping in the PSI processing can be performed more efficiently. In this study, we used a combination of DTS and PSI techniques aiming to detect high rates of linear and non-linear ground movement, based on high-resolution TerraSAR-X data acquired at relatively short 11-day intervals. The DTS results provided the first estimate of the topographic error and the phase displacement model for the PSI analysis. The proposed methodology was used to monitor ground movement in an open pit iron mine, the N5W, located in the Carajás Mineral Province (Brazilian Amazon region). Carajás has the world's largest iron reserves with mining exploration carried out through open pit benching. In the next section, a description of this particular mine as well as some related ground deformation instabilities are presented. In Section 3, the set of data used in this work is detailed. The aforementioned methodology is presented in Section 4. Moreover, this approach, with 33 TSX-1 scenes, allowed the detection of a high rate of ground movement, with a good agreement with total station/prisms and ground-based radar (GBR) measurements (real aperture radar-GroundProbe Pty Ltd.-Brisbane, Australia), as presented in Section 5. Lastly, the results and potentials are discussed for an operational monitoring which aims at mining planning and risk assessments.

\section{The Study Area}

Carajás Province, located on the easternmost border of the Amazon region, is the most important Brazilian mineral province encompassing 39 iron bodies with reserves of 18 billion tons. The province, with an area of $120,000 \mathrm{Km}^{2}$, is marked by mountainous terrains characterized by a set of hills and plateaus (altitudes from 500 up to $900 \mathrm{~m}$ ). It is surrounded by southern and northern lowlands (altitudes around $200 \mathrm{~m}$ ), with deep chemical weathering which produces thick oxisols (latosols). The lowlands are completely covered by ombrophilous equatorial forest communities with complex and multileveled canopies and numerous species [25].

The iron deposits are covered by thick, hard iron crusts (lateritic duricrusts) developed over volcanic rocks and ironstones. Specific low-density savanna-type vegetation (campus rupestres) is associated with the deposits, and shows a strong contrast (clearing) with the dense equatorial forest. Fully owned by Vale S.A. mining company, exploration in Carajás is carried out through state-of-the-art open pit benching. The current mining activities are related to two iron ore bodies (N4 and N5) and started with the N4E mine in 1984 and with the N5W mine (Figure 1) in 1998. Carajás Mining Complex produces approximately 300,000 metric tons of iron ore per day [26]. The analyzed mine N5W has an area of $4.41 \mathrm{Km}^{2}$ with a pit depth of 190 meters and maximum slope angle of $31^{\circ}$. 


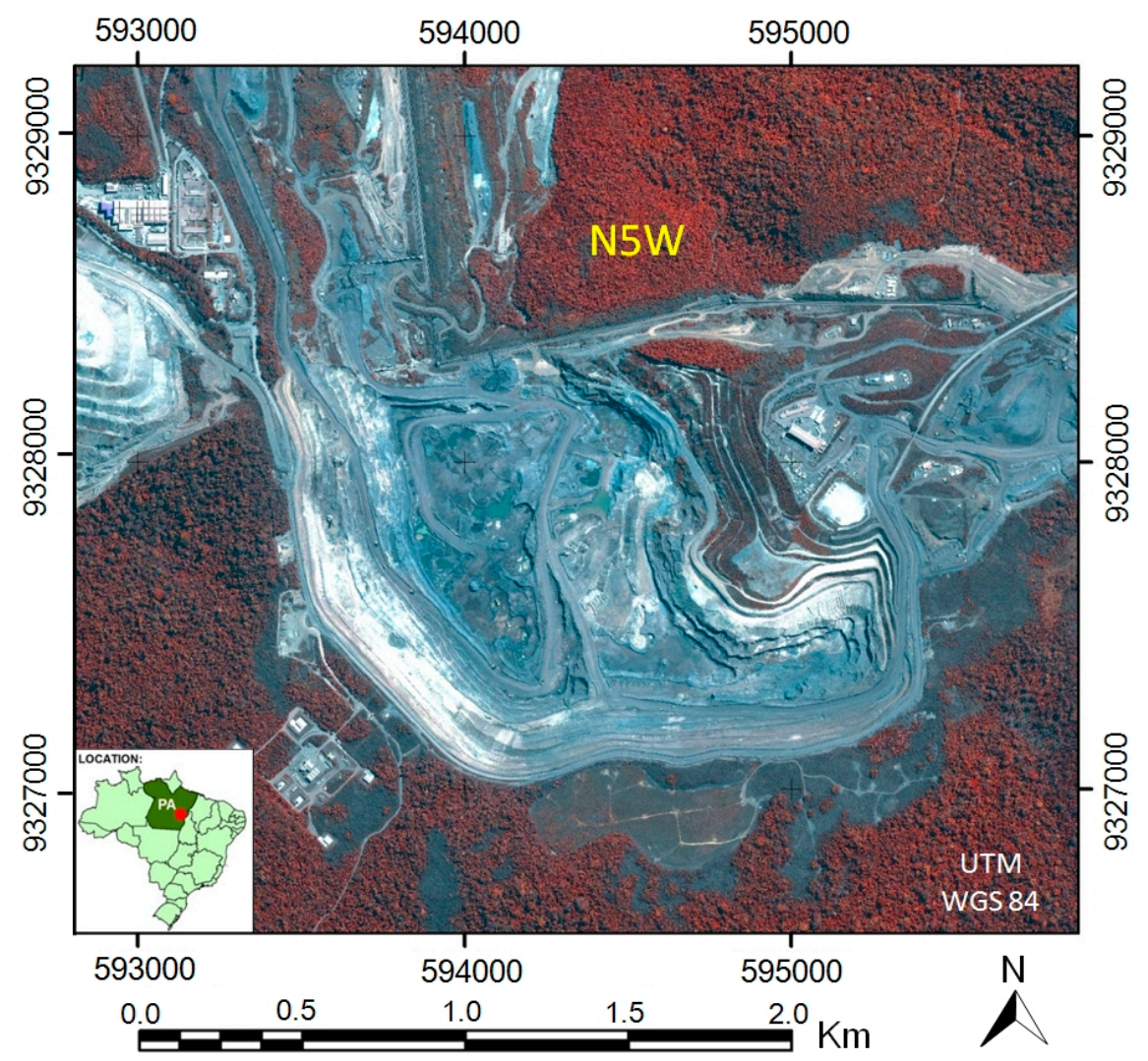

Figure 1. GeoEye-1 color composite (RGB for bands 4, 2,3) showing the N5W mine located in the Pará State (Brazilian Amazon region).

The most detailed available account of the geological and geomechanical information for the N5W open-cast pit is given by BVP [27], with surface outcrop mapping carried out at a 1:2000 scale, followed by rock classification based on mining nomenclature, characterization of structural and geomechanical parameters, with strength tests for rock units and back analysis of slope failures. Based on this report, the mine is composed by rock masses defining heterogeneous and anisotropic products with different responses to shear strength. The lithological and geomechanical classes are presented in Figure 2, as well as the interpreted lineaments extracted from photointerpretation. Mafics are country rocks of the iron ore, which are normally covered by lateritic duricrusts. Based on geotechnical parameters, the mining nomenclatures for mafics are: unweathered (fresh) mafic, weathered mafic with inferior resistance, weathered mafic with medium resistance, and semi-weathered mafic. The ironstones are classified based on physical-chemical parameters in jaspelite, soft hematite (laminated and powdery hematite), and hard hematite. Depending on the intensity of the foliations, soft hematite can be classified as strongly laminated and weak/moderate laminated. Hard hematites crop out as small lenses and small body, and sills are emplaced into these units that are covered by layered iron duricrusts, chemical crusts and lateritic soils. The main structures from detailed mapping are related to a strike-slip fault system oriented to NW-SE, (dipping to NE) and a joint system with sub-vertical trend oriented to EW. In addition, structural information extracted from photointerpretation using a stereo pair (RADARSAT-2 Ultra-Fine $x$ TSX-1 StripMap scenes) were also integrated into the final geological map. Finally, the results of strength tests and back analysis of slope failures indicated that the main lithotypes in the N5W mine, exhibited an overall poor strength ranking classification according to the RMR (Rock Mass Rating) parameters [28]. 


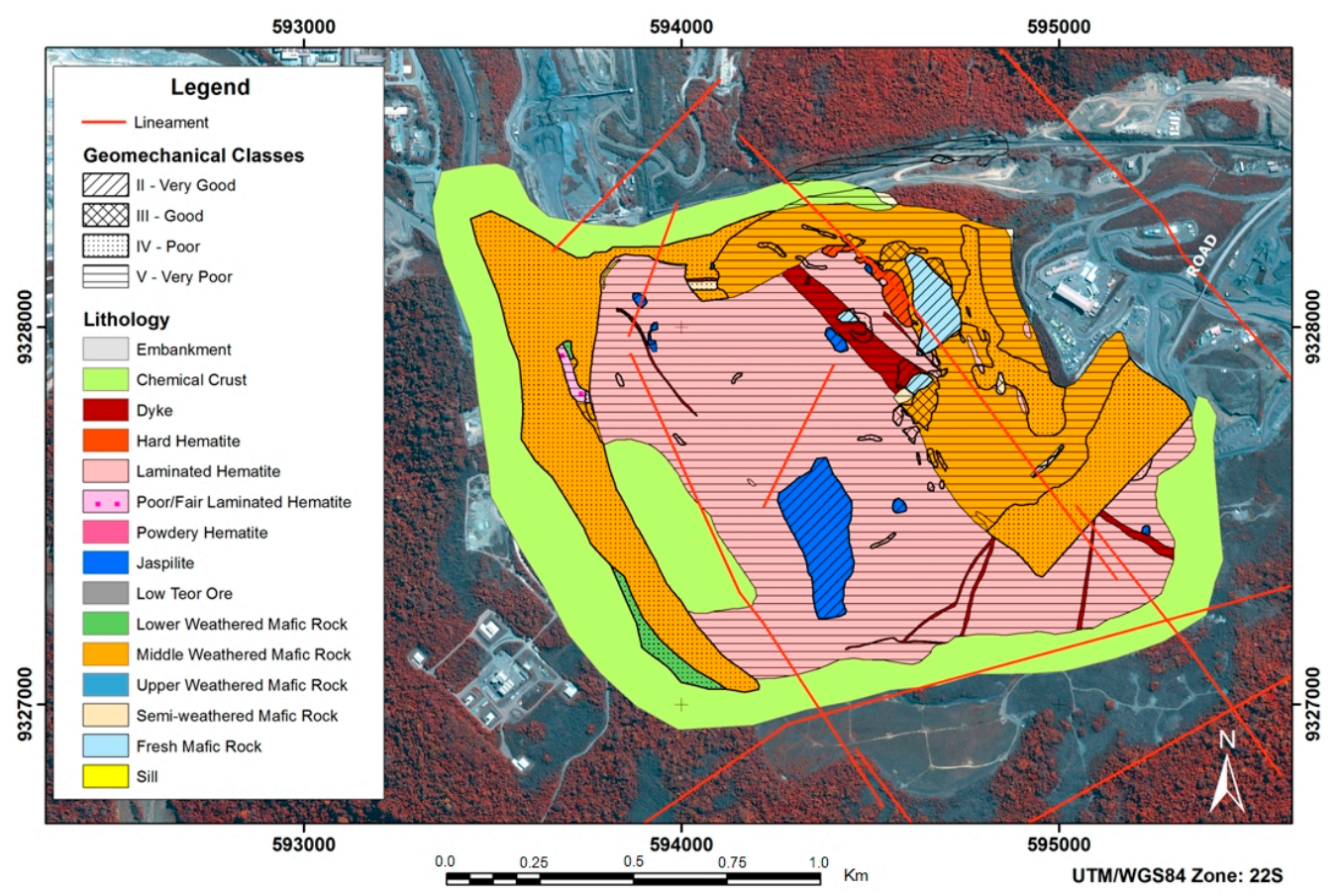

Figure 2. Geomechanical and lithological map of N5W mine with interpreted lineaments.

Signals of surface instabilities given by the presence of fractures and cracks on bench walls, berms and a road ramp have been detected by Vale's geotechnical team since the beginning of March 2012 in the SW sector of the mine. In this area, which is situated over lateritic crusts and saprolitic soils, excavations in rock alteration products of low geomechanical quality leading to the loss of slope base support caused by routine operations within the pit face, coupled with blasting practices with successive detonations causing overbreaks to the inferior benches, have contributed to the reactivation of fractures/cracks on the cut slopes. The area was systematically monitored using total station/prisms, extensometers, and for a short period by GBR. Field measurement records have shown that the onset of instabilities remained without significant evolution up to 12 August 2012, when a reactivation with relevant displacement on bench faces was detected, reaching a total variation of $10 \mathrm{~cm}$ (vertical) in the middle of September 2012 (a prism measurement). Measurements with GBR for bench walls covering the period of middle to the end of October 2012 revealed an average deformation of $14 \mathrm{~mm}$, reaching a maximum value of $16.9 \mathrm{~mm}$ (in the LoS of GBR). The geotechnical evaluation carried out by Vale S.A. in this mine sector is conclusive regarding the absence of major instabilities that could lead to large-scale movement and eventual failure [29].

\section{Satellite Dataset}

A stack with 33 TSX-1 Strip Map scenes was used to perform the investigation. The Single Look Complex (SLC) images were acquired from March 2012 to April 2013 under ascending passes (look azimuth $\sim 80^{\circ}$ ), incidence angle range of $39.89^{\circ}-42.21^{\circ}$, spatial resolution of $1.7 \times 3.49 \mathrm{~m}$ (range $\times$ azimuth), pixel spacing of $1.36 \times 1.90 \mathrm{~m}$ (range $\mathrm{x}$ azimuth) and swath width of $30 \mathrm{~km}$. A GeoEye-1 stereo-pair images acquired on 1 July 2012 was used to produce a high-resolution digital elevation model (DEM) and orthoimages (panchromatic and multispectral), with spatial resolution of $2 \mathrm{~m}$ in order to improve the differential interferometric processing [30]. A stereo-pair of RADARSAT-2 Ultra-fine (UF) scenes was used to perform a geological structure interpretation. These images were acquired on 9 and 23 July 2009, on descending passes (look-azimuth around 280 degrees), and correspond to ultra-fine beam modes (UF5 and UF 21), with spatial resolution of $3.38 \times 2.8 \mathrm{~m}$ (UF5) and $2.44 \times 2.80 \mathrm{~m}$ (UF21). 


\section{Methodological Approach}

Time-series analysis based on multiple SAR acquisitions can be performed with a set of differential interferograms generated from the co-registered image pairs, acquired at different time intervals and different geometry. The phase components presented in each interferogram came from the topography, deformation, atmosphere, orbit error, and noise. The topographic phase can be removed from a known digital elevation model. The remaining phase components can be represented by [31]:

$$
\phi_{\Delta t(x, r)}=\phi_{d r(x, r)}+\phi_{h(x, r)}+\phi_{a t m(x, r)}+\phi_{\beta(x, r)}+\phi_{\eta(x, r)}
$$

where $x$ and $r$ are the azimuth and slant range coordinates, $\phi d r$ is the phase change due to the displacement of the pixel in the satellite line-of-sight (LoS) direction, $\phi h$ is the topographic phase error, $\phi a t m$ is the atmospheric phase delay, $\phi \beta$ is the residual phase due to orbit errors and $\phi \eta$ is the phase noise.

Multi-temporal acquisitions provide the capability for detecting the temporal change of the ground movement. A time-series can be constructed by using a multi-referenced set of differential interferogram, which is normally used for DTS analysis, or a single reference image for PSI analysis. Our idea consists of combining both techniques (DTS and PSI) to achieve the detection of high rate of linear and non-linear deformation in full resolution, in an open pit mine located in Carajás Mineral Province (Brazilian Amazon), where the deformation phenomena change according to wet and dry seasons [24]. Figure 3 shows, in block diagram, the proposed integration approach using both techniques. In this approach, the DTS provides the first topographic terrain correction and the displacement phase model for the PSI analysis, in order to improve the determination of the remaining deformation and the topographic error in full resolution.

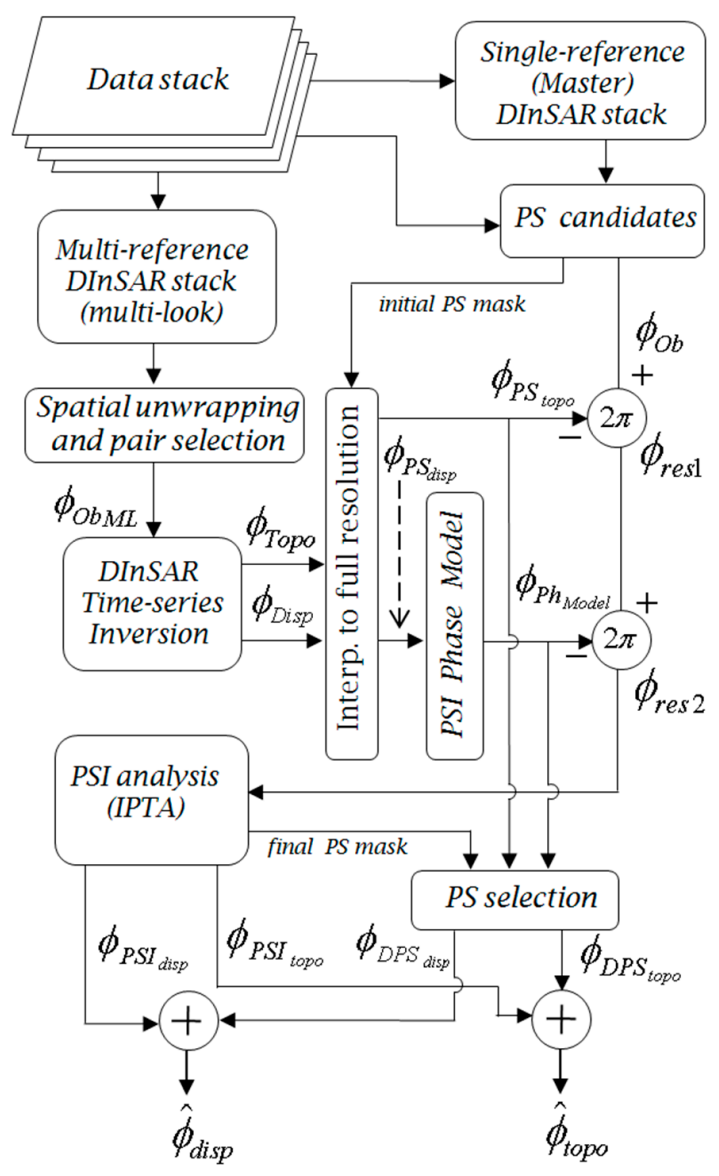

Figure 3. Block diagram of the integrated approach. 


\subsection{DInSAR Time-Series (DTS) Analysis}

The DTS technique uses a stack of multi-referenced differential interferograms (multi-look) based on a set of $\mathrm{N}+1$ SAR images acquired at the ordered time $\left(t_{0}, t_{1}, \ldots, t_{N}\right)$, where each differential interferometric pair is constructed in a given time interval $(\Delta t)$, as represented in Equation (1). A set of differential interferogram pairs can be found based on the constraint of time interval and baseline length. A group of $\mathrm{M}$ interferograms are selected based on the mean coherence threshold and visual inspection of the unwrapped interferograms. Considering a reference point assigned to a stable area and a generic point in the coordinates $(\mathrm{x}, \mathrm{r})$, the observed multi-look unwrapped phase values of this point in relation to the reference point may be organized in a vector of $\mathrm{M}$ elements, as

$$
\phi_{O b M L(x, r)}^{T}=\left[\phi_{\Delta t 1(x, r)}, \phi_{\Delta t 2(x, r)}, \ldots, \phi_{\Delta t M(x, r)}\right]
$$

The number of unknown phase values ( $\mathrm{N}$ elements) related to the range displacement of a generic point $(x, r)$ at ordered time $\left(t_{1}, t_{2}, \ldots, t_{N}\right)$, considering $t_{0}$ as a reference epoch (zero deformation), can be represented in a vector form, as

$$
\phi_{D i s p(x, r)}^{T}=\left[\phi_{d r 1(x, r)}\left(t_{1}\right), \phi_{d r 2(x, r)}\left(t_{2}\right), \ldots, \phi_{d r N(x, r)}\left(t_{N}\right)\right]
$$

The relation between range displacement Equation (3) vector and observed multi-look data vector Equation (2) can be represented as one system of $M$ equation and $N$ unknown variables in the following matrix form:

$$
A \phi_{\operatorname{Disp}(x, r)}=\phi_{\mathrm{ObML}(x, r)}
$$

where $\mathrm{A}$ is a MxN matrix of the operators $(+1,-1,0)$, which defines the operations between the unwrapped differential interferograms.

The solution of Equation (4) can be obtained in the Least Squares (LS) sense [6]. According to [7], a physically sound solution can be found in terms of mean phase velocity among time-adjacent acquisitions using the SVD decomposition, and a final integration can be used to achieve the final solution $\phi$ Disp.

We used a modified SBAS technique [7] by introducing a set of weighted constrains on the acceleration of the displacement to control the smoothness of the time-series solution [8], minimizing the atmospheric artifacts. The smoothing constraint parameters and the terms related to the derivative of the phase in relation to the height (which is proportional to the normal baseline), for topographic error estimation (he), were incorporated into the system of equation [32]. The inversion was performed by using an extension of the SVD [33], providing the mean velocity vector of the ground displacement, as follows

$$
V_{d(x, r)}^{T}=\frac{\lambda}{4 \pi}\left[\frac{\phi_{d r 1(x, r)}}{\left(t_{1}-t_{0}\right)}, \frac{\phi_{d r 2(x, r)}}{\left(t_{2}-t_{1}\right)}, \ldots, \frac{\phi_{d r N(x, r)}}{\left(t_{N}-t_{N-1}\right)}\right]
$$

The integrated displacement of a pixel in the coordinate $(x, r)$ is represented by Equation (6), considering $\mathrm{t}_{0}$ as a reference epoch (zero deformation), $d r\left(\mathrm{t}_{0}\right)=0$ and $V_{0}=0$.

$$
d r_{(x, r)}=\left(t_{1}-t_{0}\right) v_{d 1(x, r)}+\left(t_{2}-t_{1}\right) v_{d 2(x, r)}+\ldots+\left(t_{N}-t_{N-1}\right) v_{d N(x, r)}
$$

The phase displacement and the topographic phase error (he) in the coordinate $(x, r)$ are represented by Equations (7) and (8), respectively, as the output of the DTS analysis shown in Figure 3.

$$
\begin{gathered}
\phi_{\operatorname{Disp}(x, r)}=\frac{4 \pi}{\lambda} d r_{(x, r)} \\
\phi_{\text {Topo }(x, r)}=\frac{4 \pi}{\lambda} h_{e}
\end{gathered}
$$

The results of the DTS represented by Equations (7) and (8) are resampled for full resolution, in order to have the same pixel spacing as that of the differential interferograms for the PSI 
analysis. Once the results are interpolated, they are masked with the initial PS candidates, creating $\phi P S d i s p$ and $\phi P S t o p o$, which are the phase displacement and the topographic phase error in the PS positions, respectively (Figure 3). Another important transformation is performed to change the phase displacement to the PSI phase model, as represented in Equation (7), which is referenced to the master image, as used in the PSI analysis and represented by:

$$
\phi_{P h_{\text {Model }}}^{T}=\phi_{\text {Disp }}\left(t_{1}\right)-\phi_{\text {Disp }}\left(t_{\text {Master }}\right), \phi_{\text {Disp }}\left(t_{2}\right)-\phi_{\text {Disp }}\left(t_{\text {Master }}\right), \ldots, \phi_{\text {Disp }}\left(t_{N}\right)-\phi_{\text {Disp }}\left(t_{\text {Master }}\right)
$$

The phase model in Equation (9) incorporates the phase rate (linear deformation) and the non-linear deformation in relation to a reference point, located in a stable area represented by a concrete pillar that supports the ore conveyer.

\subsection{Persistent Scatterer Interferometry (PSI) Analysis}

The time-series used in the PSI analysis is based on a stack of $\mathrm{N}$ differential interferograms, generated from a set of $\mathrm{N}+1 \mathrm{SAR}$ images, in relation to a master image. Each interferogram, considered now in full resolution, can be represented as Equation (1), where the coordinate $(x, r)$ is related to a generic PS position. The idea of PSI is to analyze the temporal and spatial characteristics of the interferometric phase of individual point targets [11-13].

The PSI processing sequence includes SAR SLC image co-registration to generate the stack of differential interferograms. The master scene is selected based on a configuration that provides low perpendicular baseline dispersion positioned close to the center of the time-series, in order to maximize the interferometric coherence. The PS candidates are estimated based on the amplitude dispersion index [11] and low spectral diversity [12] at each pixel of the stack of the co-registered images. Considering a reference point located in a stable area and a selected generic PS in the coordinates $(\mathrm{x}, \mathrm{r})$, the observed wrapped phase values of this point in relation to the reference point can be organized in a vector of $\mathrm{N}$ elements, as

$$
\phi_{O b(x, r)}^{T}=\left[\phi_{\Delta t 1(x, r)}, \phi_{\Delta t 2(x, r)}, \ldots, \phi_{\Delta t N(x, r)}\right]
$$

The vector of wrapped phase represented in Equation (10) has the components of deformation, topographic error, atmospheric artifacts, orbit errors, and noise. In this work, we propose using a priori knowledge of some phase components to improve the performance of the PSI analysis.

The results obtained from the DTS analysis, the topographic error $\phi$ PStopo, represented by Equation (8), and the phase deformation model $\phi$ Phmodel, represented by Equation (9), are subtracted from the observed phase, represented by Equation (10), in order to reduce the effects of these phase components, aiming to improve the PSI analysis. As shown in Figure 3, the $\phi$ PStopo is subtracted (modulo-2 $\pi$ ) from the observed phase vector Equation (10), resulting in the first residual wrapped phase, represented in Equation (11), which is then subtracted (modulo-2 $\pi$ ) from the phase model $(\phi$ Phmodel), resulting in the second residual wrapped phase represented in Equation (12).

$$
\begin{gathered}
\phi_{\text {res } 1(x, r)}^{T}=\phi_{O b(x, r)}^{T}-\phi_{P S \text { topo }(x, r)}^{T} \\
\phi_{r e s 2(x, r)}^{T}=\phi_{\text {res } 1(x, r)}^{T}-\phi_{\text {Ph model }(x, r)}^{T}
\end{gathered}
$$

The resulting phase in Equation (12) presents the atmospheric phase component, the phase noise and the residual phase due to the errors which occurred during the DTS processing in the estimation of the topographic error as well as errors related to the phase model in Equation (9), which contain the components of the linear and non-linear deformation. Considering that the larger phase components (topography error, high rate and non-linear movement) have been removed in Equations (11) and (12), the PSI processing can be better performed to remove the remaining atmospheric phase and noise thus determining the residual deformation more precisely. 
In the proposed methodology shown in Figure 3, the PSI processing was performed using IPTA (Interferometric Point Target Analysis) technique [12] which in essence is based on a two-dimensional regression, where the phase model exploits the linear dependence of the topographic phase with the perpendicular baseline components and a linear time dependence with deformation (equivalent to a constant deformation rate). An important aspect of IPTA is the possibility of a stepwise interaction to improve different parameters. The residues of the linear regression of the deformation contain the atmospheric phase components, the non-linear deformation, and phase noise. These residues are filtered in time and in space to remove the atmospheric and noise phase components, as well as to retrieve the non-linear deformation.

It is not expected that the phase model Equation (9) will match the real deformation perfectly nor that the estimated topographic phase error Equation (8) will be very precise (due to the multi-look processing and the smoothing factor applied in DTS solution). Consequently, the obtained PSI results provide the residual topographic error and the remaining components of the linear and non-linear deformation, for a set of reliable PS that fulfills the constraint parameters related to the linear regression of the deformation, meaning that points with standard deviations above a selected threshold are discarded from the results.

The final solution for the deformation is obtained by adding the PSI result to the phase model, represented by Equation (13), and for the final topographic error, by the addition of the components from PSI analysis with the DTS, as represented in Equation (14). Only the PS present in the final_PS_mask will be valid (Figure 3).

$$
\begin{aligned}
& \hat{\phi}_{\text {disp }(x, r)}^{T}=\phi_{\text {PSI disp }(x, r)}^{T}+\phi_{\text {Ph model }(x, r)}^{T} \\
& \hat{\phi}_{\text {topo }(x, r)}^{T}=\phi_{P S I \text { topo }(x, r)}^{T}+\phi_{P S \text { topo }(x, r)}^{T}
\end{aligned}
$$

\section{Data Processing}

The multi-reference DInSAR stack for time-series analysis (DTS) was generated using the normal baseline restriction up to $800 \mathrm{~m}$ and the time interval among interferometric pairs up to 45 days. A total of 107 pairs were found and a mean coherence was computed for each one. The normal baseline size did not play an important role in the mean coherence values for this set of data [23]. It was observed that the time interval was the key point for the interferometric decorrelation, probably due to environmental characteristics of the study area (active iron mine with intense surface changes and with periods of intense rainfall, which contribute to the temporal SAR decorrelation).

All interferograms were obtained by using a complex multi-look operation, with four looks in range and four looks in azimuth. Adaptive spectral filter with window size equal to 32 by 32 was applied to the interferograms to produce interferometric coherence images [34]. Regions with coherence below 0.4 were masked out (especially in forested areas around the N5W mine), leaving $44.9 \%$ of the area $\left(4.41 \mathrm{Km}^{2}\right)$ to be analyzed. The spatial phase-unwrapping processing of the interferograms was carried out by using the algorithm MCF (Minimum Cost Flow) [35].

The selection of the differential interferometric pairs to perform the DTS was based on the criterion of the highest coherence in order to reduce phase-unwrapping errors covering the time span of the investigation. Visual inspection was also used to discard interferograms with compromising phase-unwrapping errors. Figure 4 shows the selected set of interferometric pairs (solid lines) and the discarded pairs (dashed lines). Most of the selected pairs belong to the shortest time interval among acquisitions (11 days). 


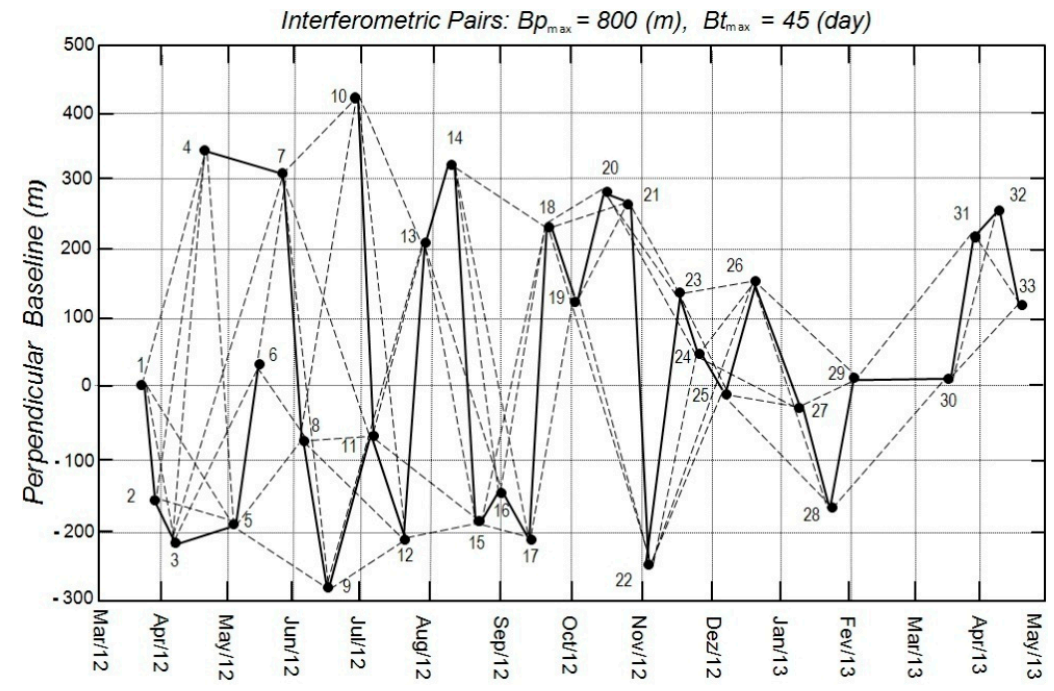

Figure 4. Interferometric pairs selected (solid lines) and discarded (dashed lines), based on the stack of 33 TSX-1 images.

For the PSI analysis, a stack of 33 co-registered SLC images was used to generate the interferometric pairs in relation to a master image, whose selection was made based on low perpendicular baseline dispersion close to the center of the time-series, as shown in Table 1.

Table 1. TSX-1 acquisition image dates, perpendicular baseline $(\mathrm{m})$ and time interval relative to the master image (4 October 2012).

\begin{tabular}{cccccccc}
\hline Pair & Date & Bperp $(\mathbf{m})$ & Days & Pair & Date & Bperp $(\mathbf{m})$ & Days \\
\hline 1 & 20 March 2012 & -90.29 & -199 & 18 & 23 September 2012 & 141.48 & -11 \\
2 & 31 March 2012 & -247.08 & -187 & 19 & 4 October 2012 & - & 0 \\
3 & 11 April 2012 & -304.35 & -176 & 20 & 15 October 2012 & 193.19 & 11 \\
4 & 22 April 2012 & 240.80 & -165 & 21 & 26 October 2012 & 182.55 & 22 \\
5 & 3 May 2012 & -282.70 & -154 & 22 & 6 November 2012 & -365.24 & 33 \\
6 & 14 May 2012 & -67.05 & -143 & 23 & 17 November 2012 & 52.94 & 44 \\
7 & 25 May 2012 & -132.00 & -132 & 24 & 28 November 2012 & -62.38 & 55 \\
8 & 5 June 2012 & -172.43 & -121 & 25 & 9 December 2012 & -114.12 & 66 \\
9 & 16 June 2012 & -391.40 & -110 & 26 & 20 December 2012 & 55.93 & 77 \\
10 & 27 June 2012 & 315.25 & -99 & 27 & 11 January 2013 & -143.35 & 99 \\
11 & 8 July 2012 & -165.18 & -88 & 28 & 22 January 2013 & -275.16 & 110 \\
12 & 19 July 2012 & -326.51 & -77 & 29 & 2 February 2013 & -97.73 & 121 \\
13 & 30 July 2012 & 110.54 & -66 & 30 & 18 March 2013 & -96.69 & 165 \\
14 & 10 August 2012 & 224.56 & -55 & 31 & 29 March 2013 & 123.33 & 176 \\
15 & 21 August 2012 & -284.61 & -44 & 32 & 9 April 2013 & 165.84 & 187 \\
16 & 1 September 2012 & -242.91 & -33 & 33 & 20 April 2013 & 25.34 & 198 \\
17 & 12 September 2012 & -317.49 & -22 & & & & \\
\hline
\end{tabular}

PS candidates were selected using two complementary criteria: the first set of PS was estimated based on a low spectral diversity [12] and the second based on the temporal variability of the scattered amplitude [11]. The two candidate sets were then combined into one list.

The outputs of the DTS analysis, $\phi$ Disp and $\phi$ Topo, were spatially interpolated to full resolution by using a bilinear algorithm. Afterwards, they were masked according to the initial_PS_mask, meaning that only the information present in the coordinates of the PS (persistent scatterer) candidates were selected. The interferograms for PSI analysis are related to the master image, which means that the deformation phase found with DTS ( $\phi$ PSdisp) needs to be reorganized to create the phase model ( $\phi$ Phmodel), as illustrated in the block diagram of Figure 2, where each layer of the stack has the deformation phase in relation to the master image, as represented by Equation (9). 
The steps before PSI analysis consist of two subtraction modulus $2 \pi$; the first is related to the topographic phase ( $\phi$ PStopo) represented by Equation (11), and the second to the phase deformation model ( $\phi$ Phmodel) represented by Equation (12). The final residual phase ( $\phi$ res2) is then used in the PSI analysis. It is expected that most of this final residual phase information be related to the contribution of the atmospheric phase, orbit errors, and phase noise. The phase components related to the deformation and topography can be considered low since the estimation of these components by DTS can be considered quite reliable [8].

As described in Section 4.2, the PSI analysis was performed with IPTA technique. The DEM error was estimated based on a linear dependence of the topographic phase to the perpendicular baseline components, which presented diversity values ranging from -7.25 up to $382 \mathrm{~m}$ for the 32 interferometric pairs. The ground displacement was estimated based on a linear time dependence to the deformation which was computed through a linear regression between time and phase variation using limited deformation rates from -5 up to $5 \mathrm{~mm} /$ years. The phase standard deviation of the linear regression was predefined to 1.2 radians, which allowed detecting and rejecting points not suitable for IPTA analysis. Atmospheric phase delay may account for most of the linear regression deviation (residues) related to the deformation. This phase component is strongly attenuated by using spatial (200 $\times 200$ samples) and temporal filtering (five samples), taking into account its characteristic of being spatially correlated and temporally uncorrelated. After removing the atmospheric and noise phase, the residual linear and non-linear deformation may account for the remaining one. After a stepwise iteration, the outputs of the PSI analysis, $\phi$ PSIdisp, and $\phi P S I t o p o$, were added to the $\phi P h m o d e l$ and $\phi P S t o p o$, respectively, providing the final ground deformation estimation ( $\phi$ disp) and the final DEM error (фtopo), as shown in Figure 3. It is important to point out that only the PS that fulfilled the PSI processing constraint was accepted, and used on the final_PS_mask.

\section{Results and Discussions}

The results of the DInSAR time-series (DTS) processing using the interferometric pairs configuration shown in Figure 4 brought richer information regarding the displacement velocity on the pit benches, as illustrated in Figure 5. The atmospheric phase artifacts were filtered out in the space-time domain and the DEM errors were estimated based on the normal baseline diversity (Figure 6). High deformation rates were detected along pit benches and ramps on the SW sector of the N5W mine. The DTS results were used to perform the PSI analysis.

The results of the PSI processing, using previous information about phase displacement model and DEM error derived from the DTS, were able to detect areas with high non-linear ground deformation rates, as shown in Figures 7 and 8. The density of the PS in the final processing was $16,365 / \mathrm{Km}^{2}$, considering only the masked area $\left(4.41 \mathrm{Km}^{2}\right)$ of the N5W mine (excluding the forested area around the mine), which can be considered of high density. High deformation was detected along pit benches and ramps on the SW sector of the N5W mine, with deformation rate up to $-340 \mathrm{~mm} /$ year, as shown in point A (Figures 7 and 8), which is associated with surface movement evidences (fractures on bench walls, tension cracks on berms and road ramps). The contribution for the ground deformation can be associated to the deep excavation on low-quality geomechanical ore/rock masses, and a structural control given by NW-SE trending shear zone and EW trending fault system, as mapped by BVP under Vale's contract [27]. 


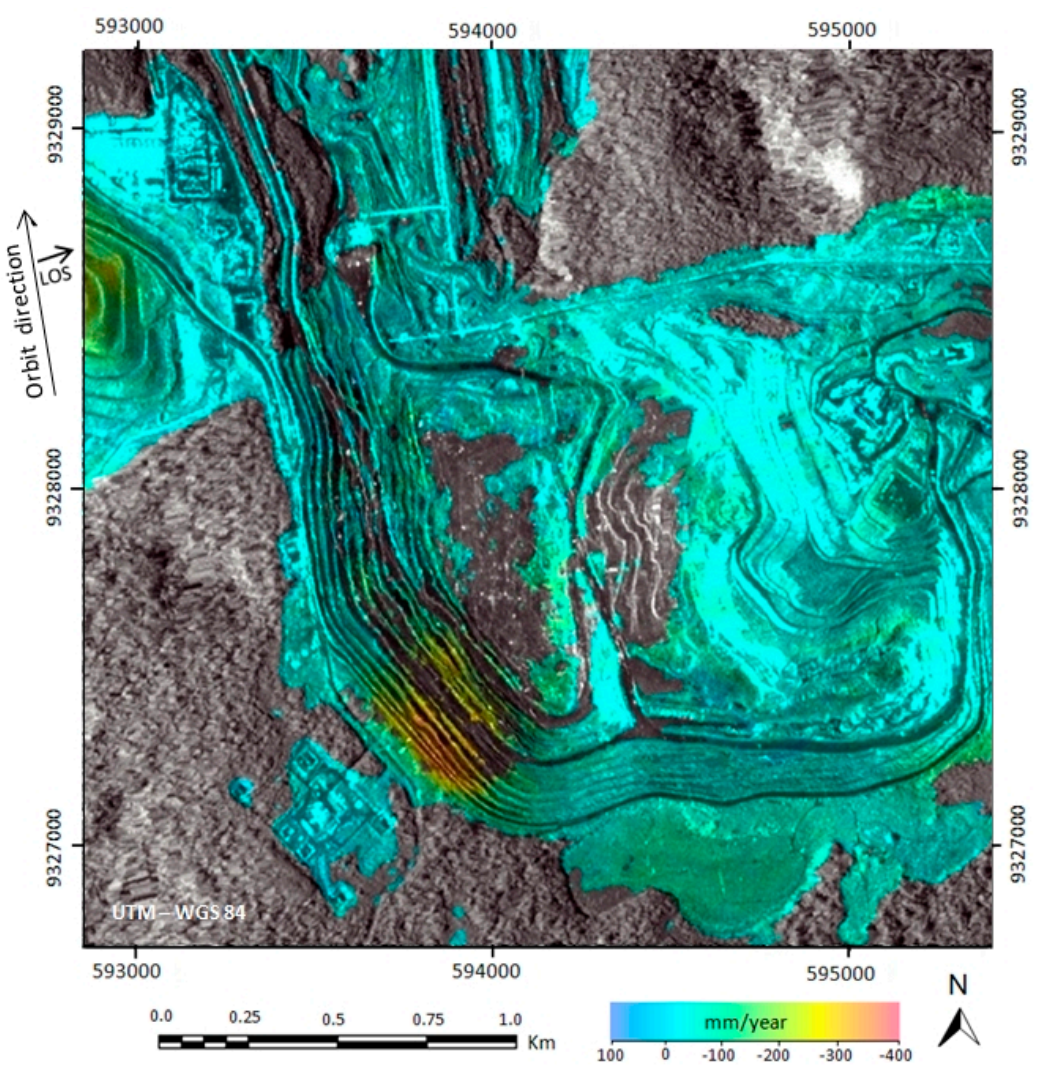

Figure 5. Displacement velocity map in LoS direction derived from DTS technique.

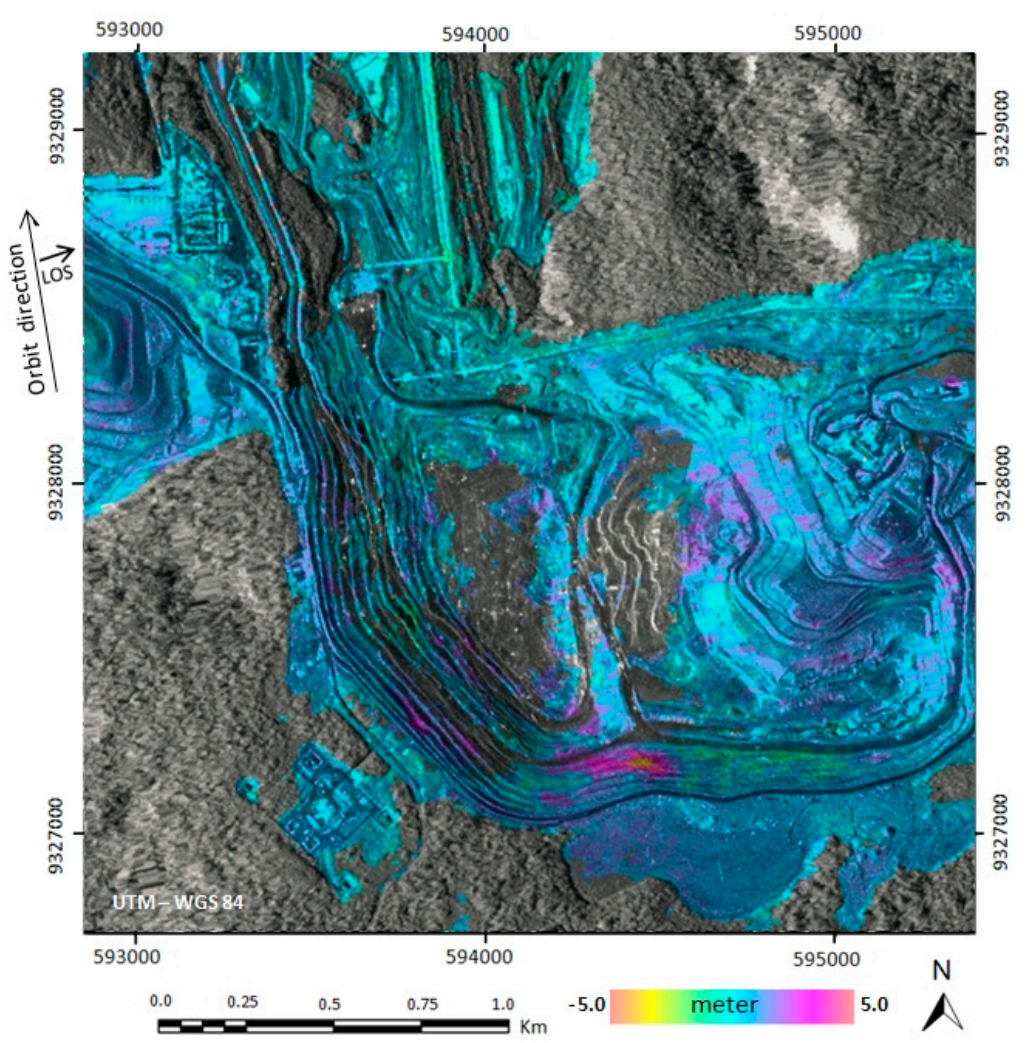

Figure 6. DEM error derived from DTS technique. 


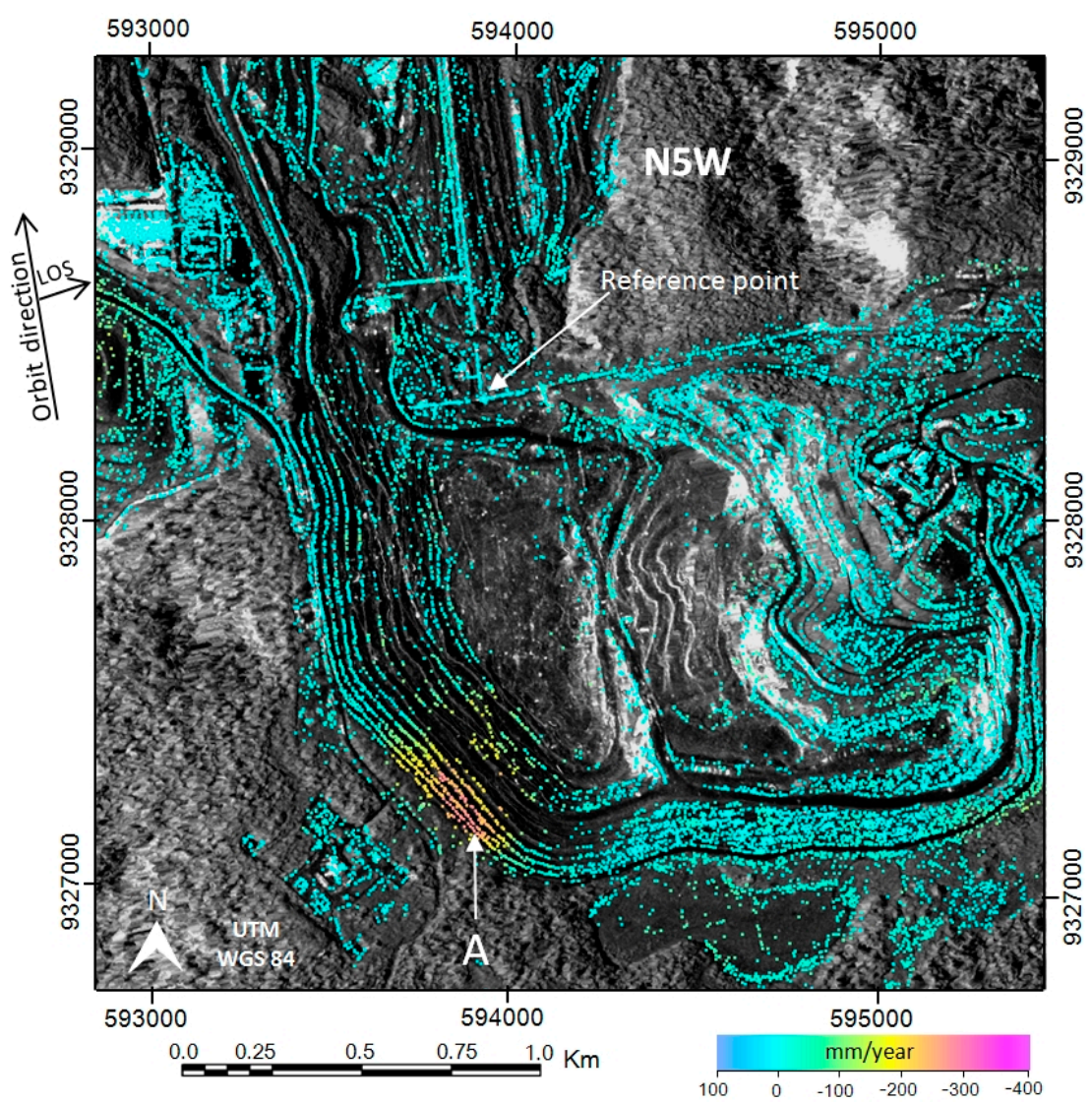

Figure 7. Displacement velocity map of the N5W mining area in LoS direction obtained by the combination of the DTS and PSI techniques.

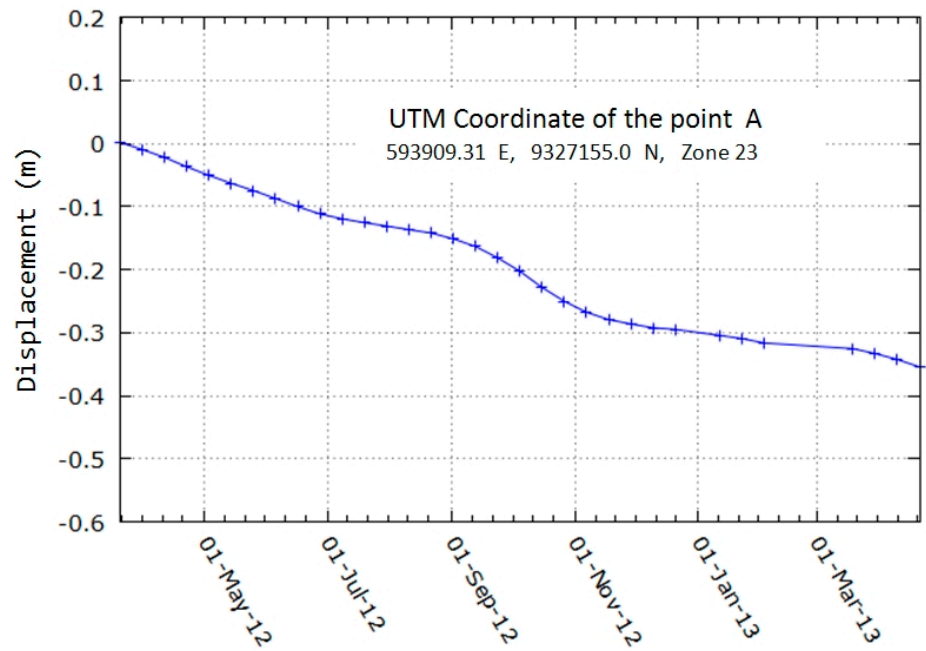

Figure 8. Ground displacement in LoS direction of point A (Figure 7) located on the pit benches.

During the period of TSX-1 acquisitions (20 March 2012 up to 20 April 2013), the N5W mine was monitored with total station/prisms, as shown in Figure 9 on the top of the pit wall (road). We compared the available prism measurements (Figure 10) from 24 April 2012 up to 28 September 2012 with PSI results (PS were selected nearby the prisms locations) at the acquisition date from 3 May 2012 up to 4 October 2012 every 11 days. 


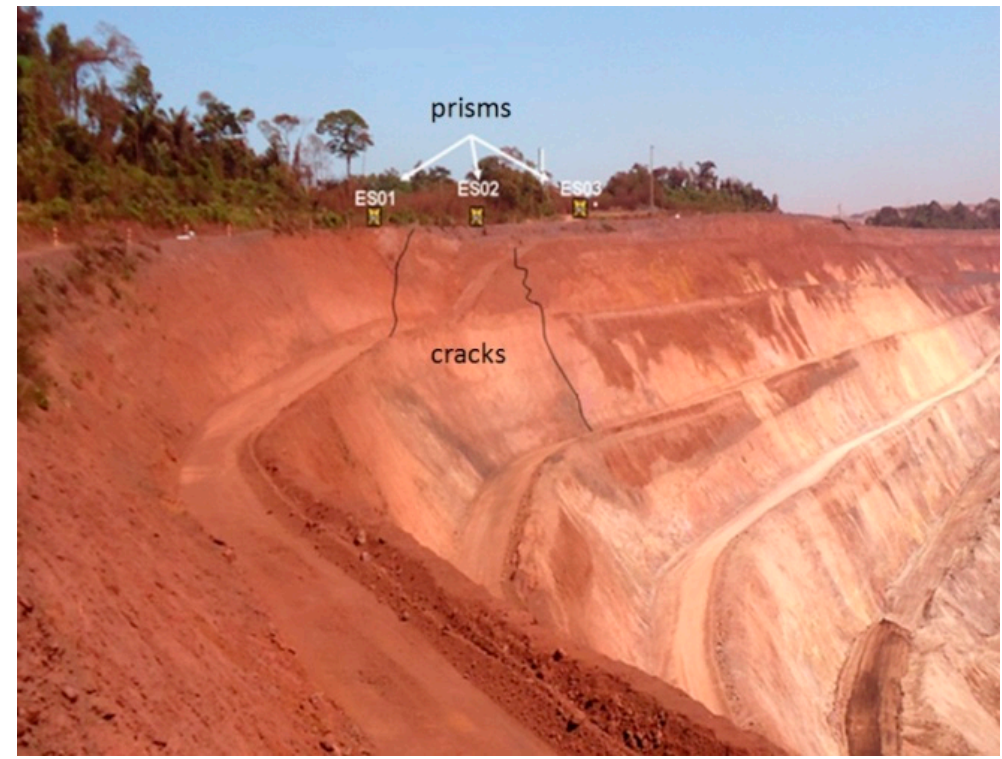

Figure 9. Presence of cracks on the pit benches related to the SW sector of the N5W mine and prisms locations.

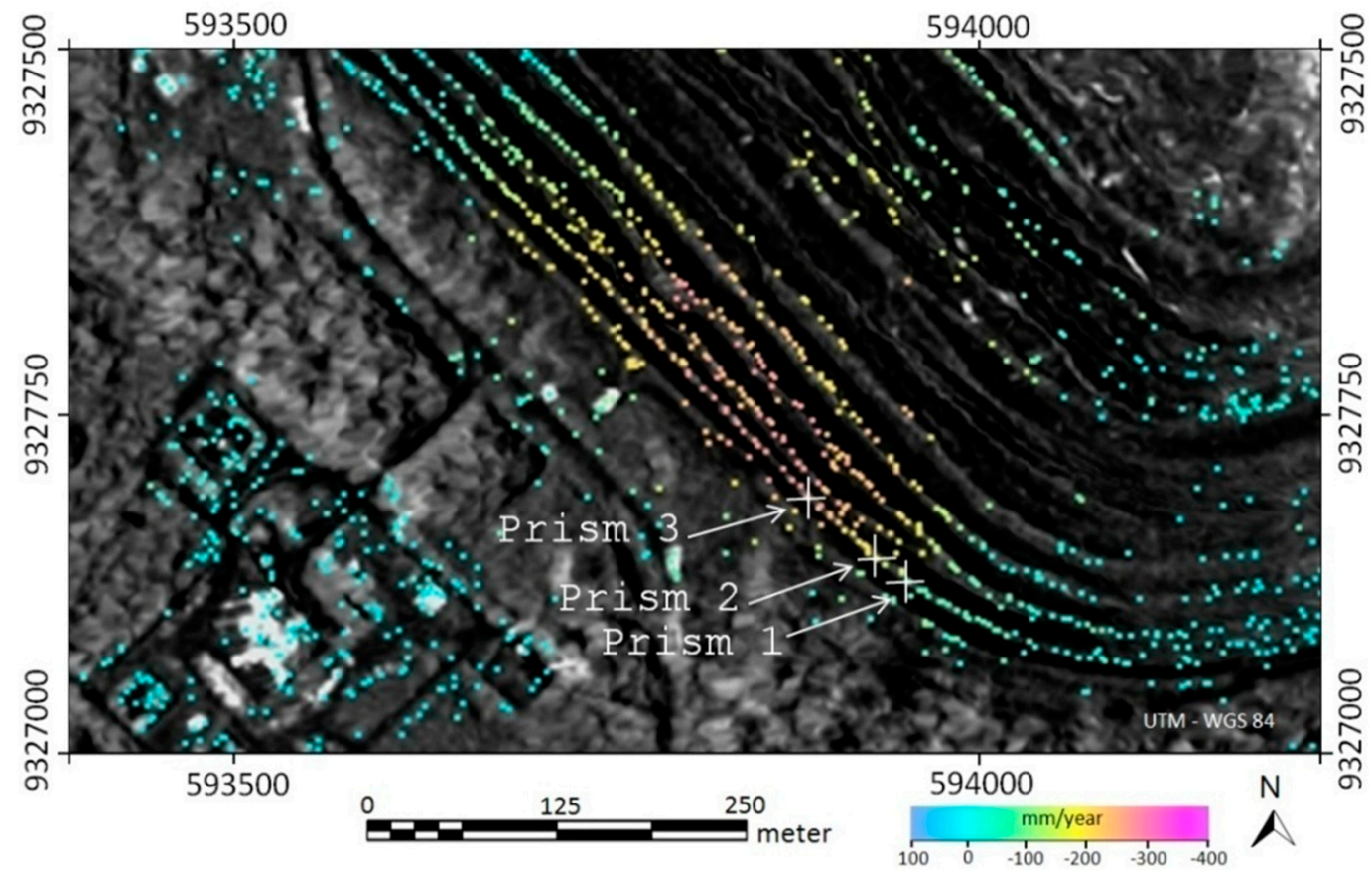

Figure 10. Picture showing the prism locations on the ground displacement map.

Figure 11 shows the topographic measurements of the prisms using total station (from 24 April 2012 up to 28 September 2012) projected in LoS direction (connected cross-points) and the PS displacements (near the prisms) represented by diamonds (from 3 May 2012 up to 4 October 2012). 


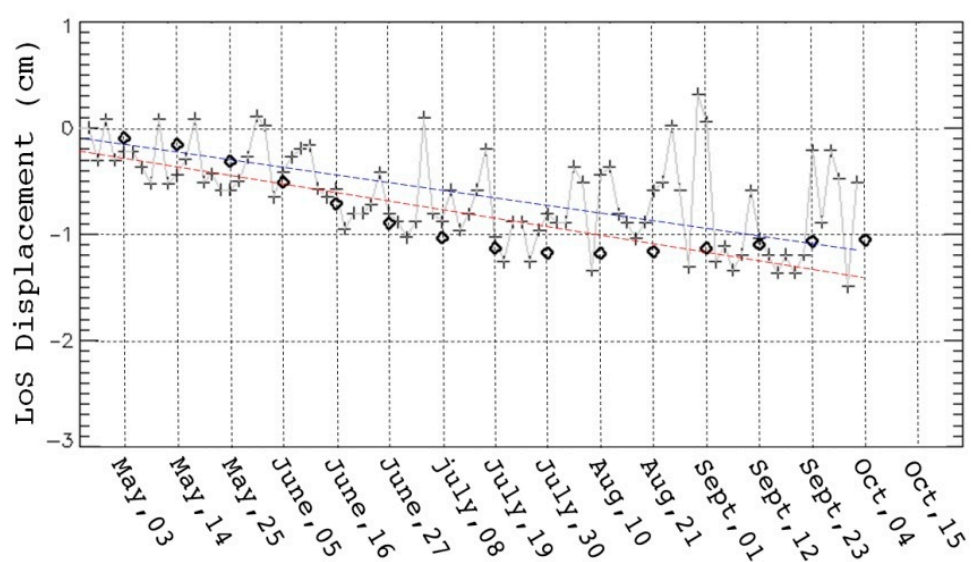

(a)

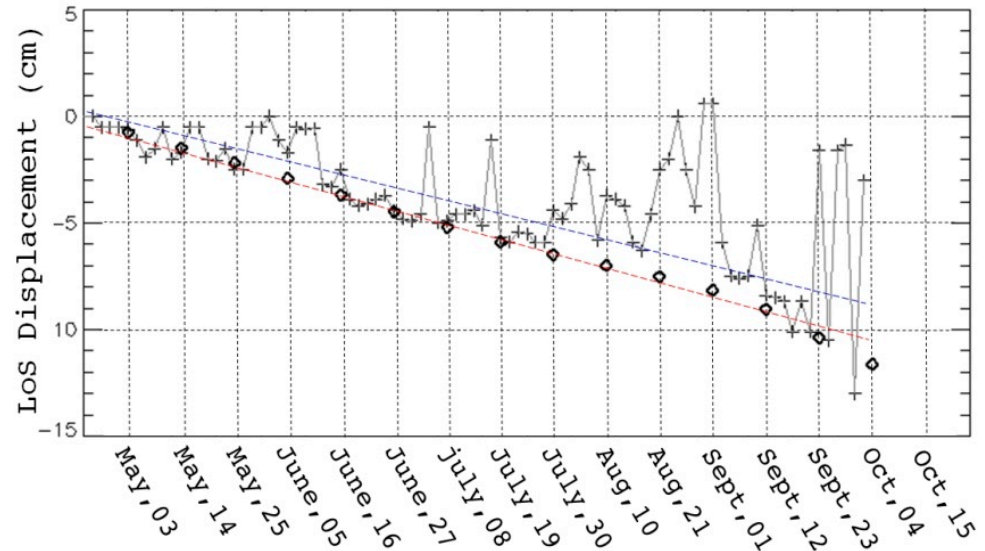

(b)

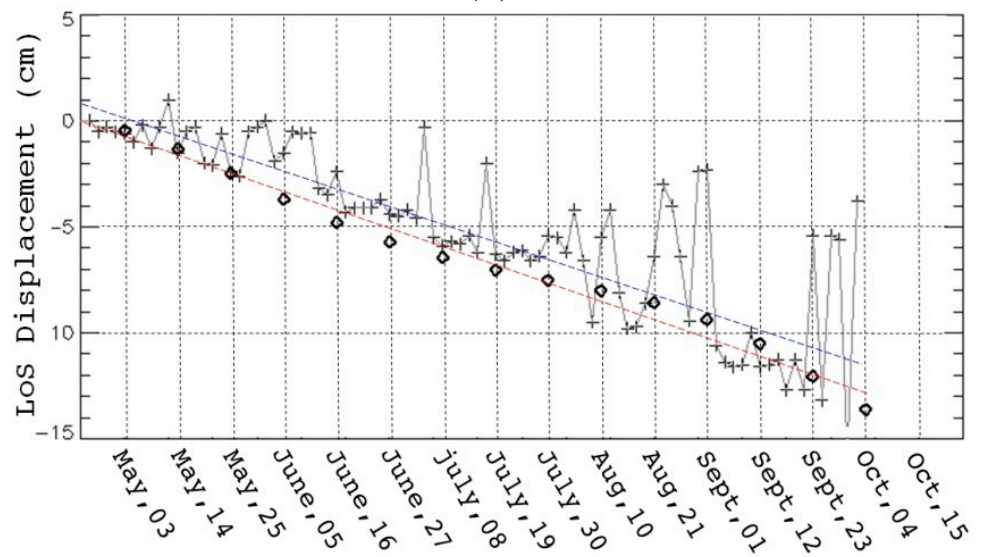

(c)

Figure 11. Topographic measurements (projected in LoS direction) represented by the connected cross-points and PS displacements (near the prism) represented by diamonds; the measurements of prism 1, 2 and 3 are shown in (a), (b) and (c), respectively; blue and red lines represent the linear regression of total station measurements and PS displacements, respectively.

We can notice from Figure 11 that the topographic measurements by total station/prisms have a high variability, probably due to the positioning of the total station at each measurement. The computed error among the PSI and prism measurements provided the following results: mean difference equal to $0.082,1.12$ and $1.27 \mathrm{~cm}$ for the prism 1,2 and 3, respectively; RMSE of $0.24,2.27$ and $1.84 \mathrm{~cm}$ for the prism 1, 2 and 3, respectively. Despite these errors, there is a good agreement with PS displacement in terms of trend, for the three prism locations. 
GBR measurement, restricted to the pit walls, was carried out in a short period of time, from 17 up to 24 October 2012. Despite the short field monitoring period, a small and continuous deformation pattern can be seen in nine points monitored on the pit wall (Figure 12), with a maximum accumulated LoS-projected GBR deformation value of $11 \mathrm{~mm}$. The GBR deformation value was not projected in the satellite line-of-sight due to the uncertainty of its positioning. The GBR measurement was taken only in this period because evidence of high deformation had been noticed with the appearance of cracks. This measurement period has a correlation with the magnification of the deformation rate which occurred from September to November, as shown on the graph of Figure 8. Later on, the Vale Company decided to re-excavate these slopes due to the deformation.
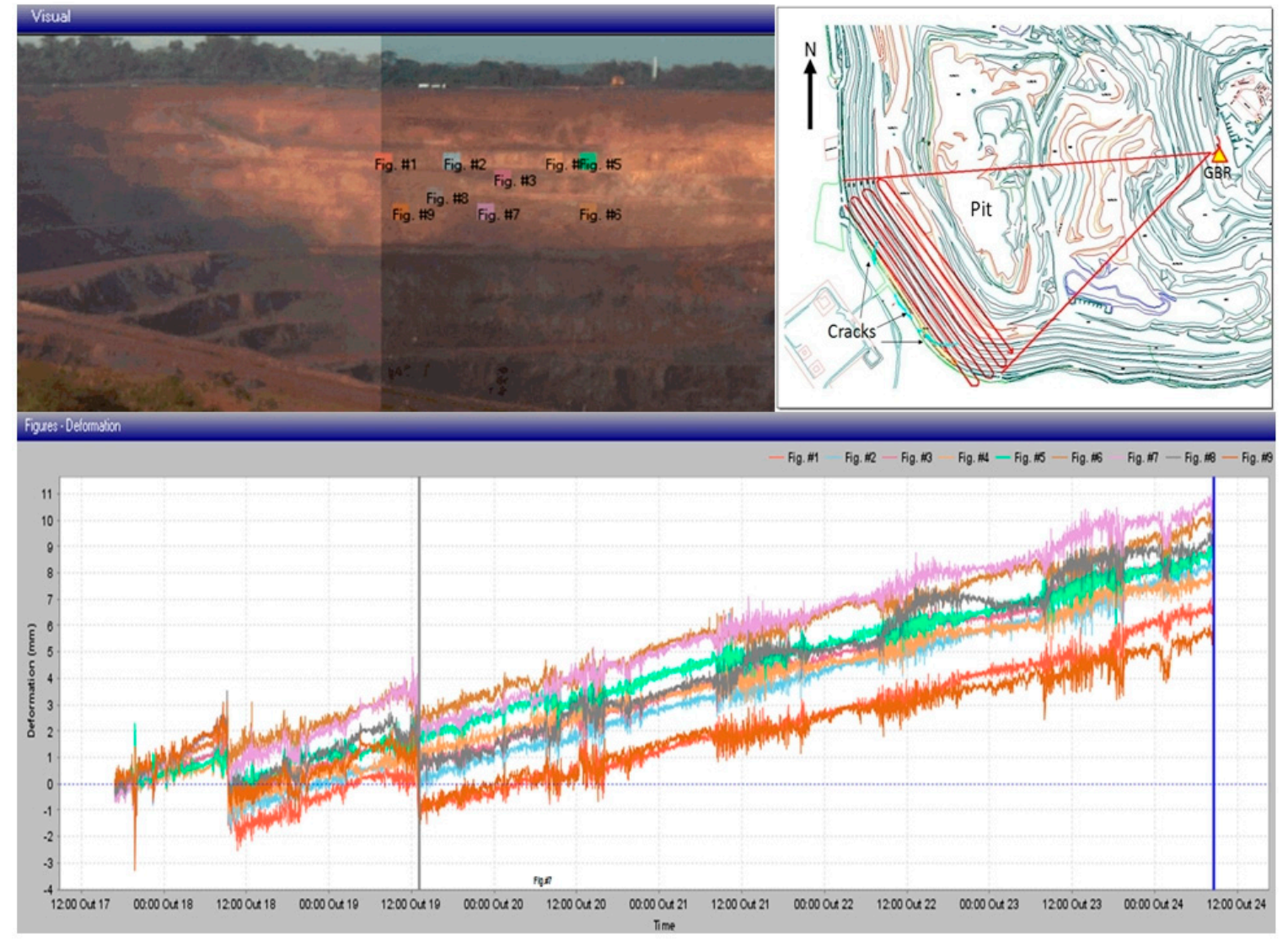

Figure 12. Monitoring using GBR in nine points on the pit wall of the N5W mine (upper part of the figure, on the left, shows the locations of the points and on the right the positioning of the ground radar). The lower part of the figure shows the graphics of the displacement in LOS-projected GBR geometry.

\section{Conclusions}

The combined DTS and PSI techniques together with high-resolution TerraSAR-X data, acquired at relatively short intervals (11-day) and covering the time span from March 2012 to April 2013, allowed detection of a high rate of linear and non-linear deformation on the N5W mining area. The main region affected by ground movement was on the pit benches located on the SW sector of the mine, reaching a value of up to $-340 \mathrm{~mm} /$ year. The main structural trends that played a key role in controlling the rock unit displacements are related to a shear system oriented to N30-40W and fractures with E-W trending direction. Deep excavations in rock masses of low geomechanical quality coupled with blasting practices and heavy precipitation contributed to the overall instabilities.

The validation was performed with total station/prism measurements limited to a time interval from 24 April 2012 up to 28 September 2012, in three positions on the pit wall. During this period, it was possible to compare topographic measurements using total station/prisms with 15 PSI results (the PS 
were selected near the prism locations) from 3 May 2012 up to 4 October 2012 every 11 days. Despite the variability of the prism data, it was possible to detect a good agreement with PSI displacement in terms of trend for the three prism locations. GBR measurements also showed evidence of ground movement despite the short monitoring time. The comparison with PSI measurement was not carried out due to the uncertainty of the GBR positioning.

This work presents a methodology that can be applied for monitoring linear and non-linear deformation in open pit mines located in a tropical rainforest environment (Amazon region), providing spatial coverage and useful information about ground movement for mining planning and risk assessment.

Acknowledgments: This investigation was carried out under the scope of a FAPESP-Vale-INPE project (Process FAPESP \# 2010/51267-9). The National Council for Scientific and Technological Development (CNPq) is also acknowledged for a grant received by the second author during the investigation. The authors would like to thank Vale S.A. for providing access to geological, geomechanical and in situ ground deformation data (GBR). Finally, the authors are particularly grateful to $t$ Vale's Geotechnical team in Carajás for the support during the field work campaign.

Author Contributions: José Claudio Mura wrote the manuscript and was in charge of SAR processing, performed with the support of Fabio Gama and Guilherme Silva. Waldir Paradella wrote the manuscript and carried out data interpretation. Mauricio Galo and Paulo Camargo carried out the field surveys. Arnaldo Silva performed the statistic analyses. Aristotelina Silva provided access to geological, geomechanical and ground deformation data from prisms and GBR. All the authors worked on the manuscript revisions.

Conflicts of Interest: The authors declare no conflict of interest.

\section{Abbreviations}

The following abbreviations are used in this manuscript:

$\begin{array}{ll}\text { DTS } & \text { DInSAR Time-Series } \\ \text { PSI } & \text { Persistent Scatterer Interferometry } \\ \text { GBR } & \text { Ground-Based Radar } \\ \text { IPTA } & \text { Interferometry Point Target Analysis } \\ \text { SBAS } & \text { Small Baseline Subset } \\ \text { MCF } & \text { Minimum Cost Flow } \\ \text { SVD } & \text { Singular Value Decomposition } \\ \text { LoS } & \text { Line-of-Sight }\end{array}$

\section{References}

1. Gabriel, A.K.; Goldstein, R.M.; Zebker, H.A. Mapping small elevation changes over large areas: Differential SAR interferometry. J. Geophys. Res. 1989, 94, 9183-9191. [CrossRef]

2. Massonnet, D.; Rossi, D.M.; Carmona, C.; Adragna, F.; Peltzer, G.; Feigl, K.; Rabaute, T.; Rabaute, T. The displacement field of the Landers earthquake mapped by radar interferometry. Nature 1993, 364, 138-142. [CrossRef]

3. Peltzer, G.; Rosen, P.A. Surface displacement of the 17 Eureka valley, California, earthquake observed by SAR interferometry. Science 1995, 268, 1333-1336. [CrossRef] [PubMed]

4. Rosen, P.; Werner, C.; Fielding, E.; Hensley, S.; Buckley, S.; Vincent, P. A seismic creep along the San Andreas fault northwest of Park field, CA measured by radar interferometry. Geophys. Res. Lett. 1998, 25, 825-828. [CrossRef]

5. Strozzi, T.; Wegmuller, U.; Tosi, L.; Bitelli, G.; Spreckels, V. Land subsidence monitoring with differential SAR interferometry. Photogramm. Eng. Remote Sens. 2001, 67, 1261-1270.

6. Usai, S. A least-squares approach for long-term monitoring of deformations with differential SAR interferometry. In Proceedings of the IEEE International Geoscience and Remote Sensing Symposium (IGARSS'02), Toronto, ON, Canada, 24-28 June 2002; pp. 1247-1250.

7. Berardino, P.; Fornaro, G.; Lanari, R.; Sansosti, E. A new algorithm for surface deformation monitoring based on small baseline differential SAR interferograms. IEEE Trans. Geosci. Remote Sens. 2002, 40, 2375-2383. [CrossRef] 
8. Schmidt, D.A.; Bürgmann, R. Time-dependent land uplift and subsidence in the Santa Clara valley, California from a large InSAR data set. J. Geophys. Res. 2003, 108, 2416-2429. [CrossRef]

9. Lanari, R.; Mora, O.; Manunta, M.; Mallorquí, J.J.; Berardino, P.; Sansosti, E. A small-baseline approach for investigating deformations on full-resolution differential SAR interferograms. IEEE Trans. Geosci. Remote Sens. 2004, 42, 1377-1386. [CrossRef]

10. Crosetto, M.; Crippa, B.; Biescas, E. Early detection and in-depth analysis of deformation phenomena by radar interferometry. Eng. Geol. 2005, 79, 81-91. [CrossRef]

11. Ferretti, A.; Prati, C.; Rocca, F. Permanent scatterers in SAR interferometry. IEEE Trans. Geosci. Remote Sens. 2001, 39, 8-20. [CrossRef]

12. Werner, C.; Wegmuller, U.; Strozzi, T.; Wiesmann, A. Interferometric point target analysis for deformation mapping. In Proceedings of the IEEE International Geoscience and Remote Sensing Symposium (IGARSS 2003), Toulouse, France, 21-25 July 2003; Volume 7, pp. 4362-4364.

13. Hopper, A.; Bekaert, D.; Spaans, K.; Arikan, M. Recent advances in SAR interferometry time series analysis for measuring crustal deformation. Tectonophysics 2012, 514-517, 1-13. [CrossRef]

14. Ferretti, A.; Fumagalli, A.; Novali, F.; Prati, C.; Rocca, F.; Rucci, A. A new algorithm for processing interferometric data-stacks: SqueeSAR ${ }^{\mathrm{TM}}$. IEEE Trans. Geosci. Remote Sens. 2011, 49, 3460-3470. [CrossRef]

15. Iglesias, R.; Mallorqui, J.J.; Monells, D.; López-Martínez, C.; Fabregas, X.; Aguasca, A.; Gill, J.A.; Corominas, J. PSI deformation map retrieval by means of temporal sublook coherence on reduced sets of SAR images. Remote Sens. 2015, 7, 530-563. [CrossRef]

16. Colesanti, C.; Mouelic, S.L.; Bennani, M.; Raucoules, D.; Carnec, C.; Ferretti, A. Detection of mining related ground instabilities using the Permanent Scatterers technique: A case study in the east of France. Int. J. Remote Sens. 2005, 26, 201-207. [CrossRef]

17. Herrera, G.; Tomás, R.; Lopez-Sanchez, J.M.; Delgado, J.; Mallorqui, J.J.; Duque, S.; Mulas, J. Advanced DInSAR analysis on mining areas: La Union case study (Murcia, SE Spain). Eng. Geol. 2007, 90, 148-159. [CrossRef]

18. Perski, Z.; Hanssen, R.; Wojcik, A.; Wojciechowski, T. InSAR analyses of terrain deformation near the Wieliczka Salt Mine, Poland. Eng. Geol. 2009, 106, 58-67. [CrossRef]

19. Ng, A.-H.M.; Ge, L.; Yan, Y.; Li, X.; Chang, H.-C.; Zhang, K.; Rizos, C. Mapping accumulated mine subsidence using small stack of SAR differential interferograms in the Southern coalfield of New South Wales, Australia. Eng. Geol. 2010, 115, 1-15. [CrossRef]

20. Wegmüller, U.; Walter, D.; Spreckels, V.; Werner, C.L. Nonuniform ground motion monitoring with TerraSAR-X persistent scatterer interferometry. IEEE Trans. Geosci. Remote Sens. 2010, 48, 895-904. [CrossRef]

21. Herrera, G.; Tomas, R.; Vicente, F.; Lopez-Sanches, J.M.; Mallorquí, J.J.; Mulas, J. Mapping ground movements in open pit mining areas using differential SAR interferometry. Int. J. Rock Mech. Min. Sci. 2010, 47, 1114-1125. [CrossRef]

22. Hartwig, M.E.; Paradella, W.R.; Mura, J.C. Detection and monitoring of surface motions in active mine in the Amazon region, using persistent scatterer interferometry with TerraSAR-X satellite Data. Remote Sens. 2013, 5, 4719-4734. [CrossRef]

23. Mura, J.C.; Paradella, W.R.; Gama, F.F.; Santos, A.R. Monitoring of surface deformation in open pit mine using DInSAR time-series: A case study in the N5W Iron Mine (Carajás, Brazil) using TerraSAR-X data. Proc. SPIE 2014. [CrossRef]

24. Paradella, W.R.; Ferretti, A.; Mura, J.C.; Colombo, D.; Gama, F.F.; Tamburini, A.; Santos, R.A.; Novalli, F.; Galo, M.; Camargo, P.O.; et al. Mapping surface deformation in open pit iron mines of Carajás Province (Amazon Region) using an integrated SAR analysis. Eng. Geol. 2015, 193, 61-78. [CrossRef]

25. Paradella, W.R.; Silva, M.F.F.; Rosa, N.A.; Kushigbor, C.A. A geobotanical approach to the tropical rain forest environment of the Carajás Mineral Province (Amazon region, Brazil), based on digital TM-Landsat and DEM data. Int. J. Remote Sens. 1994, 15, 1633-1648. [CrossRef]

26. Daynes, W. 2013-Vale Brazil-Carajás Iron Ore Mine, Business Excellence, Simply ore Simply ore-inspiring. Available online: http:/ / www.republicofmining.com/2013/01/31/vale-brazil-carajas-iron-ore-mine-bywill-daynes-business-excellence-january-30-2013 (accessed on 02 December 2015).

27. BVP. Lithostructural and Lithogeomechanical Mapping of the N5W Mine; BVP Internal Report for Vale Mining Company: Belo Horizonte, Brazil, 2011. (In Portuguese)

28. Bieniawski, Z.T. Engineering Rock Mass Classifications; John Wiley \& Sons: New York, NY, USA, 1989. 
29. Vale, Sociedade Anônima. Geotechnical Evaluation for the Cracks Area in the Raymundo Mascarenhas Road and Cut Slopes of the N5W Pit, N5W Iron Mine; Vale's Internal Report; Vale, Sociedade Anônima: Belo Horizonte, Brazil, 2012. (In Portuguese)

30. Paradella, W.R.; Cheng, P. Using Geoeye-1 stereo data in mining application: Automatic DEM generation. Geoinformatics 2013, 16, 10-12.

31. Hanssen, R. Radar Interferometry; Kluwer: Amsterdam, The Netherlands, 2001.

32. Werner, L.C.; Wegmueller, U.; Strozzi, T. Deformation time-series of the lost-hills oil field using a multi-baseline interferometric SAR inversion algorithm with finite difference smoothing constraints. In Proceedings of the AGU Fall Meeting, San Francisco, CA, USA, 3-7 December 2012.

33. Golub, G.; Loan, C. Matrix Computations; John Hopkins University Press: Baltimore, MD, USA, 1989.

34. Goldstein, R.M.; Werner, C.L. Radar interferogram filtering for geophysical applications. Geophys. Res. Lett. 1998, 25, 4035-4038. [CrossRef]

35. Constantini, M. A novel phase unwrapping method based on network programming. IEEE Trans. Geosci. Remote Sens. 1998, 36, 813-820. [CrossRef]

(C) 2016 by the authors; licensee MDPI, Basel, Switzerland. This article is an open access article distributed under the terms and conditions of the Creative Commons Attribution (CC-BY) license (http:/ / creativecommons.org/licenses/by/4.0/). 